\title{
RETROSPECTIVE ASSESSMENT OF RISK TO NATURAL HAZARDS
}

\author{
C. A. Velásquez ${ }^{1}$, O. D. Cardona ${ }^{2}$, M. L. Carreño ${ }^{3}$, A. H. Barbat ${ }^{4}$
}

\begin{abstract}
The existing disaster databases allow analyzing losses produced by previous events and assessing the risk to natural hazard in a similar way as the insurance industry does for vehicles, health, etc., if the conditions and trends are maintained. Among the existing disaster databases, we selected DesInventar whose vast majority of records correspond to "small" events; this selection is of special interest as these small events are often ignored because, individually, they only stroke a few assets accounting for low economic losses. Nevertheless, their accumulated effect can have a significant impact over the economic and fiscal sustainability of urban areas, regions or countries. Also, considering the difficulties involved in assessing risk for those small disasters, like the lack of general models and the elevated susceptibility to local variables of the results, this approach can give answers so far unavailable. The methodology herein proposed has been applied to the assessment of risk (in the terms of the loss exceedance curve) in 23 countries.
\end{abstract}

Keywords disaster risk; retrospective assessment of risk; loss exceedance curve.

\section{Introduction}

The assessment of risk due to natural hazards (e.g. landslide, volcanic, hydrometeorological, hurricane, drought and tectonic) is a task of special concern for the communities settled in hazard prone areas, for the local authorities responsible for the welfare of the population, for the academic community which wants to understand and predict the occurrence of those hazards and also for entities dedicated to improving the living conditions of the communities $[1,2,3,4]$. The disasters caused by natural hazards undermine the capacities and resources of the affected communities. Furthermore, when those disasters impact recurrently the same settlements, the

\footnotetext{
${ }^{1}$ PhD Student. Universitat Politècnica de Catalunya, C/. Jordi Girona 31 - 08034 Barcelona (Spain). cavelasquez@cimne.upc.edu

${ }^{2}$ Professor. Universidad Nacional de Colombia, Sede Manizales. Cr. 27 No 64-60 Manizales (Colombia). odcardonaa@unal.edu.co

${ }^{3}$ Researcher, Centre Internacional de Mètodes Numèrics en Enginyeria (CIMNE), Universitat Politècnica de Catalunya, Campus Norte UPC C/Gran Capitán S/N, 08034, Barcelona, Spain. liliana@cimne.upc.edu

${ }^{4}$ Prefessor, Universitat Politècnica de Catalunya, Centre Internacional de Mètodes Numèrics en Enginyeria (CIMNE), Campus Norte UPC C/Gran Capitán S/N, 08034, Barcelona, Spain. alex.barbat@upc.edu
}

International JournalofDisasterRiskReduction10(2014)477-489

http://dx.doi.org/10.1016/j.ijdrr.2014.05.005 
reconstruction and recovering processes can be interrupted and the consequences of the disasters get deeper. The destruction of assets and the restriction of the capital formation are some of those consequences that also increase the poverty of the members in the affected community and reduce their capacity for adapting and handling future events.

Extensive risk is related to small but disperse disasters (e.g. landslides, floods) which can occur over large areas but affecting small settlements. Modeling small disasters is a difficult task, especially at country level, due to the large amount of information required and to the susceptibility of the results to the local data (like topography or soil mechanics), that is, the results have a high variability over small changes of these input data. Even more, the exposure data will also require details only available in big cities but not in rural areas. Nevertheless, the effects of this extensive risk, taking into account their high occurrence rate, can deplete the available resources of the affected communities and worsen the consequences of future disasters and, therefore, financial strategies for their management are required $[5,6]$.

The small disasters are generally evaluated at country level by using susceptibility maps which indicate areas of high, medium or low risk; those maps are generated based on local characteristics related to the proneness of these hazards. This approach, which allows a better planning and land-use policies, lacks the characteristics required for a risk assessment; therefore it is not possible to obtain the required metrics. The most important and robust risk metric is the average annual loss, AAL. The AAL can be defined as the amount of resources required to be saved annually in order to cope with all the future losses over a large period of time; even so, if in the short time these savings are not enough, they will be compensate during future and less catastrophic periods.

The study of the consequences of individual disastrous events is a complex task. The adequate assessment of the impact upon the economic, macroeconomic, social and environmental sectors requires a qualified staff, a large amount of information and periods of time long enough for accounting these consequences. . Usually, due to the complexity and the data requirements, this evaluation is performed only on catastrophic events that compromises consolidated economic sectors. But after a small disaster (i.e. a few persons or a small area affected), the governmental help is low or inexistent and it is the affected population that has to assist itself and reconstruct its lost assets. These small disasters are, in some way "invisible" to the national and in some cases even to the regional authorities.

Without trying to solve all the elements of the complex task of assessing the economic loss caused by a disaster, the main objective of this article is proposing a simple methodology which allows estimating the losses at local level. This loss value is related to the resources that a local govern has to spend in order to cope with the replacement or repair of the affected assets, according to its fiscal responsibility. This model is necessary due to the limited amount of data available from previous disasters, especially in the case of minor disasters. The proposed assessment, even if hypothetical and 
conservative, shows the amounts of resources that the disasters (particularly the small ones) require from local authorities. This problem is relevant in developing countries, in which the real magnitude (social and economic) of the small disaster has yet to be accounted.

Once the economic losses are estimated, the "small" natural disasters risk can be assessed. This retrospective risk assessment employs an approach similar to the insurance industry, in which data from previous years are statistically processed in order to obtaining a premium for a given sector (e.g. automotive, health, life, home). Finally, using these results, the retrospective loss exceedance curve can be obtained. This curve is of special importance, because it can relate, based on the observed data, economic losses with their expected occurrence frequency; it shows how often an economic loss has occurred or has been surpassed and, if the trends are kept, how often could it be expected or surpassed in the future. Figure 1 provides a basic scheme of the retrospective risk assessment process.

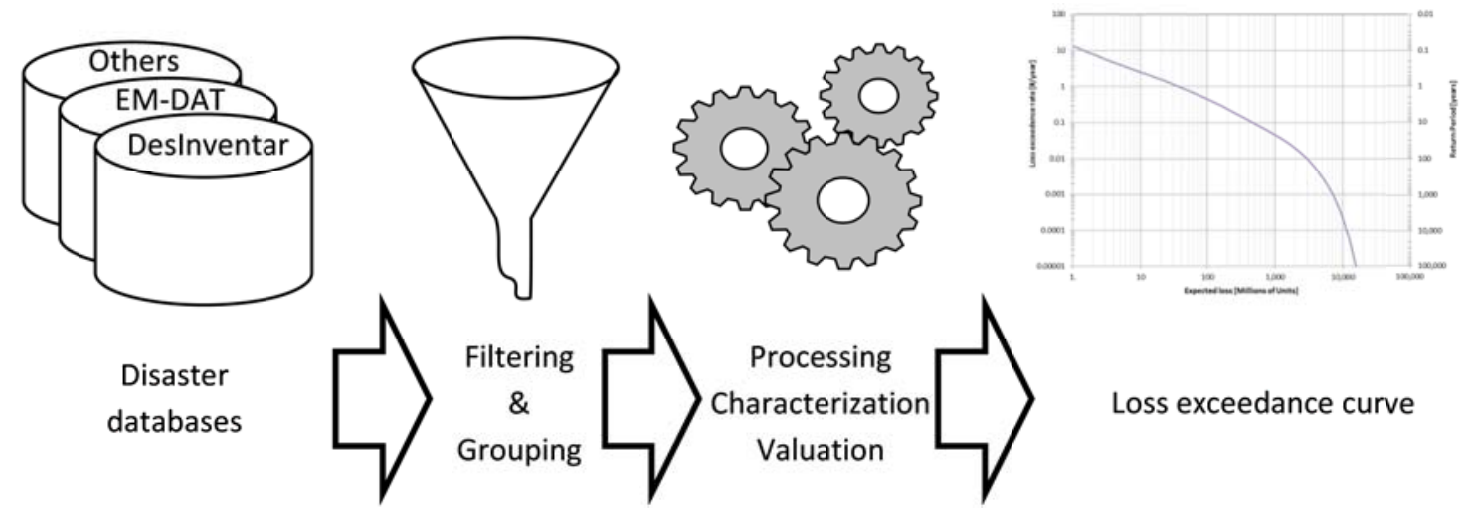

Figure 1 General scheme of the retrospective risk assessment process

Posteriorly, these results can be coupled with the outcomes of a prospective assessment that accounts for future events, which are yet to occur and for which no records exist. These two segments conform the hybrid loss exceedance curve or HLEC [7, 8, 9, 10]. The prospective assessment can represent the risk for the low frequency events which, due to their expected magnitude and intensity, can have catastrophic consequences (as they can impact simultaneously large areas and several urban centres). The prospective assessment can be made by methodologies like CAPRA [11], which accounts for the uncertainty in the event (location, magnitude and how it manifests itself), the uncertainty in the exposed assets (building response to the event) and the uncertainty in the used models. This assessment of intensive risk is required due to the lack of historical data regarding catastrophic events and the need to anticipate credible future economic losses which, in case of occurrence, could compromise the fiscal sustainability of the affected region or even the country. The HLEC is a more complete and robust representation of disaster risk, as it accounts for the small disasters (by the means of a retrospective assessment) that cannot be modeled at a country level due to limitations previously discussed; and, complementarily, for the big or catastrophic 
disasters (which can affect simultaneously a large number of elements) and were evaluated by a prospective approach [10].

The objective of this article is to develop a model for retrospective assessment of natural hazards risk. It will allow appraise a minimum cost that a disaster had incurred over the affected society in a simple and replicable approach. This model assesses a minimum loss on each event, and also the amount of resources needed for future disastrous events if the current tendencies are kept. Results obtained by using the proposed retrospective methodology are finally presented for several countries.

\section{Disaster databases}

Recording the consequences of past events, including cause and location, allows depicting a general image of areas prone to natural hazards and the severity of the different phenomena involve; and, at the same time, it allows the study of important volumes of information highly relevant for hazard and risk studies, avoiding the lengthy and expensive process of manually searching and retrieving those consequences for each one of the studies and reports available at the considered area. Unfortunately, disasters occurred a few decades ago lack the proper report of the consequences and require, in many cases, an extensive and expensive search over public documents. The availability of a disaster's catalogue, prevent those events of been forgotten and allows that lessons from them could be assimilated and used in the future.

The disaster databases do not store the complete catalogue of historic disasters; instead they are collecting the more complete set of events (including if possible previous but well documented events). This means that in the best case, there will be available a sample of events large enough to be studied and from which recommendations could be obtained. Nevertheless, it is important remembering that the information and data stored can have errors and requires a permanent review.

Two databases are evaluated in this paper, based on their public availability, their update cycle, and the type of consequences reported. Nevertheless, there are other disaster databases like NatCat and Sigma, but those are not of public access, and are based mainly on insurance claims; this fact makes them slanted on countries where the insurance industry have a limited coverage.

\section{$2.1 E M-D A T$}

The international disaster database EM-DAT [12] was developed in 1988 and is currently updated and maintained by the Centre for Research on the Epidemiology of Disasters (CRED) of the Université catholique de Louvain. It keeps a complete inventory of global disasters, which are over a specific threshold. Any event to be stored in the disaster database has to meet at least one of the following criteria:

- 10 o more people reported deaths, or

- 100 or more people reported affected, or 
- Have a declaration of state of emergency, or

- Call for international assistance.

In this disaster database, the reports from the United Nations agencies have the highest priority, followed by the reports of the Office of Foreign Disaster Assistance (USAID/OFDA), governmental reports and finally the International Federation of Red Cross and Red Crescent Societies (IFRC). This redundancy permits a constant review of the disaster information and, in some cases, including events that are not attended by all the listed agencies.

\subsection{DESINVENTAR}

The DesInventar database has been continuously updated since its inception in 1993 by the non-governmental organization "Network of Social Studies in the Prevention of Disasters in Latin America” (LA RED). Conceived as an inventory of the disasters effects, that everyday affects each one of the country's settlements. Currently two similar but different databases are maintained, one for the Americas countries [13] and one for the rest of the world [14].

Table 1 Countries in which the database has been implemented

\begin{tabular}{|c|c|}
\hline \multicolumn{2}{|c|}{ Asia } \\
\hline Country/Region & Period \\
\hline East Timor & $1992-2013$ \\
\hline India - Orissa & $1970-2012$ \\
\hline India - Tamil Nadu & $1968-2011$ \\
\hline Indonesia & $1815-2012$ \\
\hline Iran & $1895-2011$ \\
\hline Jordan & $1981-2012$ \\
\hline Laos & $1990-2012$ \\
\hline Lebanon & $1980-2011$ \\
\hline Nepal & $1971-2011$ \\
\hline Sri Lanka & $1965-2012$ \\
\hline Syria & $1980-2009$ \\
\hline Vietnam & $1989-2010$ \\
\hline Yemen & $1971-2011$ \\
\hline Maldives & $1946-2008$ \\
\hline India - Mizoram & $1992-2010$ \\
\hline India - Uttar Pradesh & $1991-2005$ \\
\hline Islas Solomon & $1568-1964$ \\
\hline Vanuatu & $549-2010$ \\
\hline
\end{tabular}

\begin{tabular}{|l|r|}
\hline \multicolumn{2}{|c|}{ Africa } \\
\hline Country/Region & \multicolumn{1}{c|}{ Period } \\
\hline Djibouti & $1944-2012$ \\
\hline Ethiopia & $1901-2010$ \\
\hline Kenya & $1997-2012$ \\
\hline Mali & $1994-2012$ \\
\hline Mozambique & $1979-2012$ \\
\hline Uganda & $1933-2012$ \\
\hline Morocco & -2011 \\
\hline Egypt & $1980-2010$ \\
\hline
\end{tabular}

\begin{tabular}{|l|c|}
\hline \multicolumn{2}{|c|}{ America } \\
\hline \multicolumn{1}{|c|}{ Country/Region } & Period \\
\hline Argentina & $1970-2009$ \\
\hline Bolivia & $1970-2011$ \\
\hline Chile & $1970-2011$ \\
\hline Colombia & $1914-2012$ \\
\hline Costa Rica & $1968-2012$ \\
\hline Ecuador & $1970-2011$ \\
\hline El Salvador & $1900-2012$ \\
\hline Guatemala & $1988-2011$ \\
\hline Guyana & $1972-2012$ \\
\hline Honduras & $1915-2011$ \\
\hline Jamaica & $1973-2012$ \\
\hline México & $1970-2011$ \\
\hline Nicaragua & $1992-2011$ \\
\hline Panamá & $1929-2012$ \\
\hline Peru & $1970-2011$ \\
\hline Uruguay & $1959-2011$ \\
\hline Venezuela & $1530-2012$ \\
\hline Dominican Republic & $1966-2000$ \\
\hline Trinidad \& Tobago & $1970-2000$ \\
\hline
\end{tabular}

Source: desinventar.net, Junio/2013.

This database collects the information at city/village level, and because of this resolution one disastrous event can be reported in several records, one per each affected settlement.

DesInventar uses information from governmental entities and collaborating NGO's but, due to the detail level and the small size of many events it also requires the use of other sources like, newspapers. The information stored in the DesInventar database requires a permanent review; it has been found during consecutive reviews data from sensationalist newspapers, official reports with inflated values and transcription errors. 
These inconsistences are generally difficult to be solved due to the lack of redundancy, but using statistical technics, e.g. OutLiers [15], they can be reduced.

\section{Economic loss model}

The estimation of the losses induced by a disaster is a complex task that requires specialized staff, a large amount of data and enough time to process the different effects over the society. The ECLAC handbook [16] is a comprehensive guide that studies the disaster impact over social and economic sectors, the infrastructure, the environment the employment and income and the macroeconomic variables. Evaluating the economic effect of hundreds or thousands of records included in a disaster database requires the use of a methodology different than the ECLAC handbook or similar; it requires a simpler methodology easily replicable and quick, which only considers the effect of the disasters upon the public and vulnerable sectors. For this, a review of the elements that are affected commonly during a disaster and are usually reported has to be done.

The proposed loss model is based on the assumption of the fiscal responsibility of the local government toward the more vulnerable and fragile society sectors, because it shares some blame (due to the lack or inadequate building codes, the lack of building controls, the inadequate protection of the infrastructure) or because it is mandate by the country laws. Although the definition and scope of the fiscal responsibility varies between countries [17], for this paper it will be defined as the government solidarity after the disaster with the vulnerable population; consequently the vulnerable population is defined as the social sector that does not have the resources to overcome the event.

The estimated loss will be the disaster minimum cost upon the society, taking into account only social elements. That is, a destroyed house will be replaced by a social housing solution even if the original one has other characteristics. This limitation is, in part, due to the reported data, in which only generic information is gathered; and is also based on the fiscal responsibility idea, according to which the replaced item will be a social element with the minimum requirements available.

The objective of the proposed methodology is establishing the minimum cost that a disaster had incurred over the affected society in a simple and replicable approach. Therefore, this methodology cannot be compare with more robust methodologies in which several sectors are study in detail. This model assesses a minimum loss on each event, and also the amount of resources needed for future disastrous events if the current tendencies are kept.

\subsection{Assumptions}

The following assumptions are made for the proposed economic loss model:

- Only elements that could be considered as fiscal responsibility will be included (e.g. houses, health centers, schools and roads). 
- The destroyed houses will be considered as total loss, it means, the full element will be replaced.

- For the damaged houses a mean value of $25 \%$ will be used. It means that, in average repairing four (4) damaged houses will cost the same as building a new one.

- The replacement value of the different elements will not include the cost of the building site. The current building area could be reused, or the government could assign a new area for these elements.

- The model will not include indirect costs (e.g. shelter, demolition and hauling), neither macroeconomic losses.

- The model will not include the value of the belongings, equipment or any kind of element different from the construction.

- Losses over crops and cattle belonging to vulnerable population, which in some cases could be object of relief policies, will be ignored. This limitation is due to the difficulty of filter the reported disaster impact of vulnerable sectors from the one of industrial and wealthy sectors, the lack of detailed reports that allow knowing what was lost (i.e. only the total area of crops affected is reported) and, finally, because the economic loss is function of the type of element (crop/cattle) and the stage at the productive cycle on which they are at the moment of the disaster (i.e. the loss is different when planted than when is ready to harvest).

- The model will not include the damage upon forests, because often it is the nature the one in charge of reforesting the burned area.

- The only damage to infrastructure considered in the model will be the damage to roads. This is due to the difficulty of assessing the replacement cost of other infrastructure elements in which costs are dependent on the element characteristics (for example, in the case of bridges costs depend on their length, elevation, etc.).

- The model will not consider human affectation. There are technical and moral issues regarding those fields.

- The calculated economic loss will be expressed in US Dollars. This will be useful for review and comparison among different countries.

\subsection{Economic valuation of houses}

To assess the effect of disasters on houses, it is required to define the cost and characteristics of a basic unit. The replacement and reparation cost of the houses damaged or destroyed by the disaster will be based upon a single family social housing unit, although the social housing characteristics have changed over the years and are different from country to country. In most cases the definition of what a social housing solution is not stated and it is left to the social welfare agencies criteria (e.g. in Colombia, before 2004, was the internal housing agency the one in charge to define the characteristics of the social housing solutions; after, a governmental decree defined the 
basic characteristics for this classification); furthermore their characteristics change among agencies and among countries.

Table 2Table 2 shows different values of area and cost for single family social housing units in some Latin-American countries. The data has been retrieved from laws or decrees of several Latin American countries, social welfare agencies publications and architectural books related. The reported areas are, in most cases, for non-developed units what means that an expansion (e.g. second story) could be built in the future.

Table 2 Characteristics for social housing solutions on some Latin-American countries

\begin{tabular}{|l|c|c|c|l|}
\hline Country & Source & Period & Minimum area & \multicolumn{1}{|c|}{ Maximum value } \\
\hline Argentina & {$[18]$} & 2007 & $44 \mathrm{~m} 2$ & - \\
\hline Peru & {$[19]$} & $>1999$ & No specify & 35 Tax units (UIT) \\
\hline Colombia & {$[20,21]$} & $1990-2003$ & $32 \mathrm{~m} 2$ & $135 \mathrm{MMW}$ \\
\hline Colombia & {$[22,23]$} & $2004-2013$ & $35 \mathrm{~m} 2$ & No specify \\
\hline Colombia & {$[24]$} & $>2013$ & No specify. & $70 \mathrm{MMW}$ \\
\hline México & {$[25,26]$} & $>2010$ & $48.8 \mathrm{~m} 2$ & $117 \mathrm{MMW}$ (Distrito Federal) \\
\hline Uruguay & {$[27]$} & $>1968$ & $32 \mathrm{~m} 2$ & \\
\hline
\end{tabular}

* MWM: Minimum monthly wage.

The 2003 ECLAC handbook [16] was aware of the complexity of the problem of correctly assess the houses worth, because of the large number of typologies, sizes, materials, and others elements related to the houses; and recommend the use of the monthly minimum wage as an indicator for the cost of the damaged houses, making it equal to the cost of one square meter of construction. It can be noticed in Table 2Table 2 how several countries relate the price of the social housing with the minimum wage; this relation takes into account the purchasing power of the population for which these policies are designed and allows certain flexibility in the cases where the cost of the building area could be an important factor.

\section{Social housing area}

Table 2Table 2 shows the different areas of social housing solutions and how those areas have changed over time. For this model, we will assume the area of an individual unit of $45 \mathrm{~m}^{2}$, taking into consideration that the values of $32 \mathrm{~m}^{2}$ and $35 \mathrm{~m}^{2}$ are for nondeveloped units, and that the population density obtained with the proposed area is between 15 and $9 \mathrm{~m}^{2} /$ inhabitant for families with 3 to 5 members.

\section{Value per area unit}

To define the economic value for the replacement of a damaged house, we require a replicable methodology on which the basic data could be easily acquired. Taking into account that indicators (e.g. minimum wage) are not available for all the countries and that, furthermore, those can change internally between regions, cities or in the case of the minimum wage upon the related activity. We will employ the Gross Domestic Product per Capita (GDP per capita) for estimating the economic value per square meter of construction. To find the relation between the GDP per capita and the area unit of social housing constructions we use the "Global Construction Cost and Reference Yearbook" [28]. Figure 2Figure 1 shows the relation for 93 countries between the 
minimum costs of construction per unit area reported in the yearbook and the GDP per capita [29] which have a correlation $\left(\mathrm{R}^{2}\right)$ of $59 \%$ with the best fitting line; the same exercise using the construction minimum wage [28] has a correlation of $40.7 \%$ with the corresponding best fitting line.

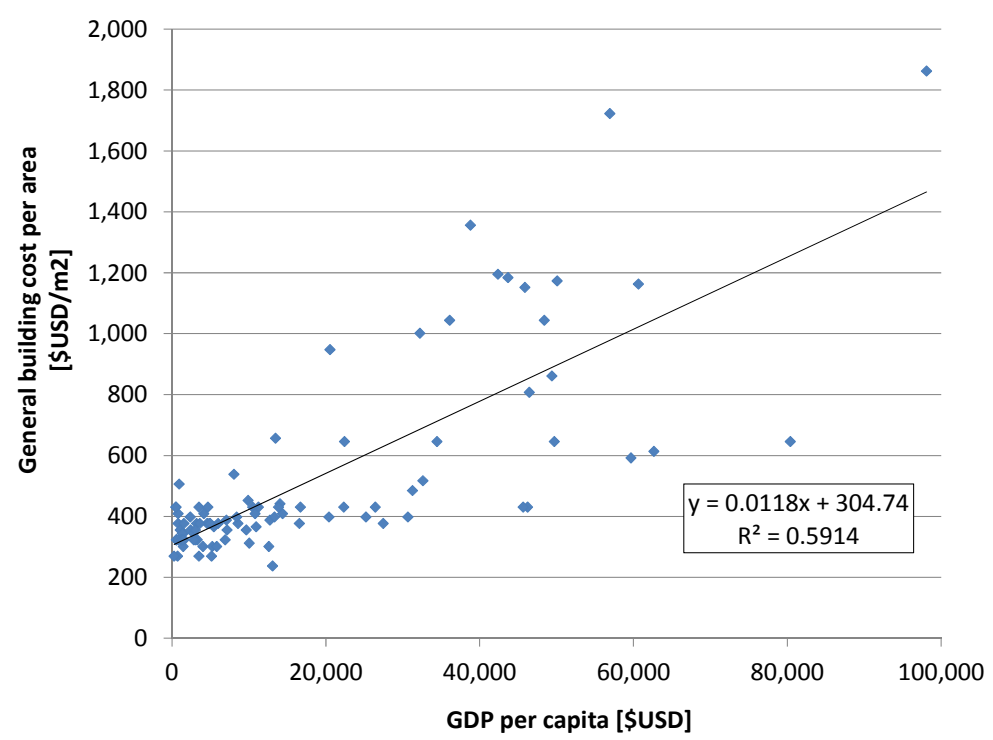

Figure 2 GDP per capita and construction cost relation, using data from 93 countries.

The best fitting line, its equation and correlation with the data is also plotted.

Figure 2Figure 2 does not show a clear tendency. Therefore, we repeat the exercise using only the countries reporting social housing construction, using a smaller sample of 16 countries and not the initial sample of 93 countries. Figure 3Figure 2 shows the new analysis, between the construction cost per unit area and the GDP per capita, on which a correlation of $85.7 \%$ with the best fitting line is obtained, for the case between the minimum wage a correlation of $80 \%$ with the best fitting line was obtained.

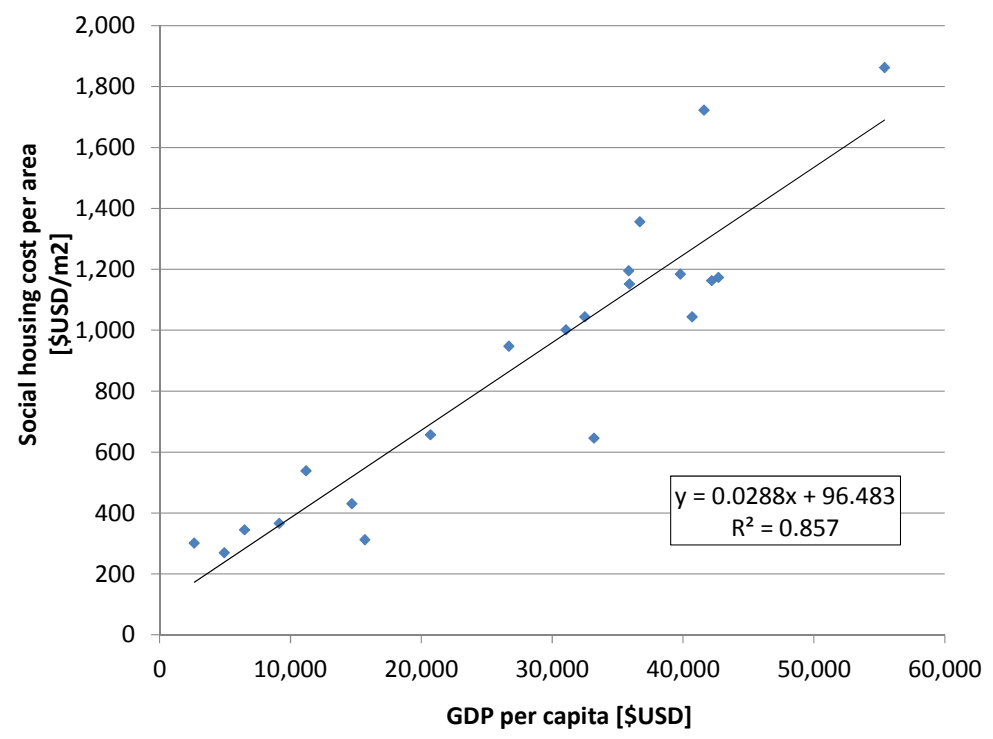

Figure $\underline{3} z$ GDP per capita and construction cost relation, using data from 16 countries.

The best fitting line, its equation and correlation with the data is also plotted. 
Finally, a factor considering the cost of the construction area preparation (i.e. the cost related to domestic utilities, roads, sidewalks and parks) is included; this factor was calculated using a small sample of data from the national planning bureau (DNP) of Colombia, obtaining a mean factor of $40 \%$. This value will be assume, because it is a function of several factors (like topography, number of units, distance to the utilities network, distance to the supplies, etc.) which cannot be considered with the necessary detail.

\subsection{Economic valuation of schools and health centers}

The schools and health centers are usually defined by their services to the community (i.e. primary and/or secondary education, first aid, small clinic, city or regional hospital) but not by the building constructed area. In order to consider the effect of the disasters over those elements, the model requires setting a minimum area, required by each of those elements to perform its social function. The area herein defined is will be multiplied by the construction value per square meter previously obtained for the social housing units.

For the scope of the present methodology, and taking into consideration the social function of these buildings, its assume that, if the construction has been destroyed or damaged by the disaster, it will be reconstructed on a less hazard prone area; thus, the cost of the replacement of the element will be the total asset value. The model will not consider the supplies and equipment, only the direct cost of the building.

Table 3 Fable 3 shows the assumed minimum elements that a basic school will require for fulfilling its social function. Correspondingly Table 4 Table 4 shows the minimum elements for a basic health center.

Table 3 Estimated school basic area

\begin{tabular}{|c|c|c|c|}
\hline \multicolumn{1}{|c|}{ Element } & amount & Dimensions & Area \\
\hline Classroom & 2 & $5 \times 6 \mathrm{~m}$ & $60 \mathrm{~m} 2$ \\
\hline Administration & 1 & $3 \times 4 \mathrm{~m}$ & $12 \mathrm{~m} 2$ \\
\hline Storage & 1 & $1 \times 3 \mathrm{~m}$ & $3 \mathrm{~m} 2$ \\
\hline \multicolumn{1}{|c|}{ Total } & & & $\mathbf{7 5 ~ \mathbf { m } 2}$ \\
\hline
\end{tabular}

Table 4 Estimate health center basic area

\begin{tabular}{|l|c|c|c|}
\hline \multicolumn{1}{|c|}{ Element } & amount & Dimensions & Area \\
\hline Lobby & 1 & $3 \times 4 \mathrm{~m}$ & $12 \mathrm{~m} 2$ \\
\hline Consulting room & 1 & $3 \times 4 \mathrm{~m}$ & $12 \mathrm{~m} 2$ \\
\hline Emergency room & 1 & $5 \times 4 \mathrm{~m}$ & $20 \mathrm{~m} 2$ \\
\hline Storage Total & 1 & $2 \times 2 \mathrm{~m}$ & $4 \mathrm{~m} 2$ \\
\hline \multicolumn{2}{|c|}{ T8 m2 } \\
\hline
\end{tabular}




\subsection{Economic valuation of roads}

For the cost of roads, we will use the information from the World Bank project: ROCKS ("ROad Costs Knowledge System”) [30]. This project has collected data from over 40 countries and, among other items, it includes at global and regional level the following costs: construction, improvement and rehabilitation. ROCKS [30] database reports the costs in USD corresponding to the year 2000; thus a correction is require, which is included in Table 5 Table 5.

Table 5 Inflation rate correction for USD [31]

\begin{tabular}{|c|c|c|c|c|c|}
\hline Year & $\mathbf{2 0 0 0}$ & $\mathbf{2 0 1 0}$ & $\mathbf{2 0 1 1}$ & $\mathbf{2 0 1 2}$ & $\mathbf{2 0 1 3}$ \\
\hline & 1.00 & 1.27 & 1.31 & 1.33 & 1.35 \\
\hline
\end{tabular}

To determinate the average national cost of a road per length unit, we require the percentage of participation of the different materials in the country's total. The World Bank Indicators System [32] only gives the percentage of asphalted roads against the total length by country; to be conservative with the costs the model considers that gravel roads are the complementary part. For the cases in which there is not an available value for the indicator [32] for the evaluation year, the most recent reported value will be used. Table 6Table 6 and the Figure 4Figure 3 display the cost of road reconstruction per kilometer for the world and several continents [30].

Table 6 Average cost of road reconstruction per kilometer, USD2000 [30]

\begin{tabular}{|c|c|c|c|c|c|}
\hline \multirow{2}{*}{ Material } & \multicolumn{5}{|c|}{ Region } \\
\cline { 2 - 6 } & World & Asia & Africa & Latin America & Europe \\
\hline Ground & 23,978 & n.d. & 25,774 & 14,996 & n.d. \\
\hline Gravel & 47,391 & 59,250 & 42,273 & 38,246 & n.d. \\
\hline Asphalt & 231,071 & 231,367 & 217,221 & 176,010 & 258,430 \\
\hline Concrete & 247,697 & 214,023 & n.d. & 310,955 & 622,198 \\
\hline
\end{tabular}

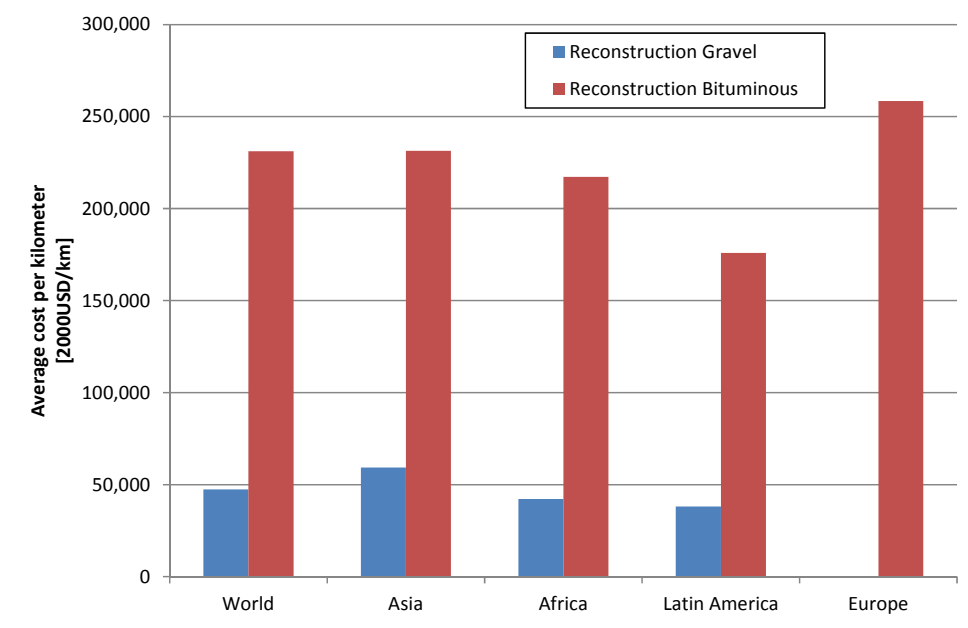

Figure $\underline{4} 3$ Average cost of road reconstruction per kilometer, Asphalt and gravel in USD2000. [30] 


\section{Methodology for the retrospective assessment of risk}

The different steps for the assessment of the economic losses caused by disasters are given below. Using this assessment, the losses due to previous disasters can be obtained and also their effects can be measured. The effect of the disasters, in particular of the small and frequent ones, has severe consequences for the development and the poverty level of the affected communities.

\subsection{Database selection}

There are two disaster databases that have the required characteristics: EM-DAT [12] and DesInventar $[13,14]$; but there are important differences, that make them more or less suitable for the proposed model. The consequences threshold required for the recording, the number of fields used to describe the effects, and the geographic level upon which the disaster effects are recorded are some of the differences between the databases; but these are also the main characteristics required by the proposed model, therefore the DesInventar disaster database was selected as the most suitable for performing the proposed analysis. Table 7Table 7 and Figure 5Figure 4 show the number of records for a specific country available in each of those databases; it can be noted that from a statistical analysis, the DesInventar database is more robust.

Table 7 Number of records available per disaster database for Colombia

\begin{tabular}{|c|c|c|}
\hline Database & Period & Records \\
\hline DesInventar & $1914-2011$ & 30,761 \\
\hline EM-DAT & $1906-2011$ & 228 \\
\hline
\end{tabular}

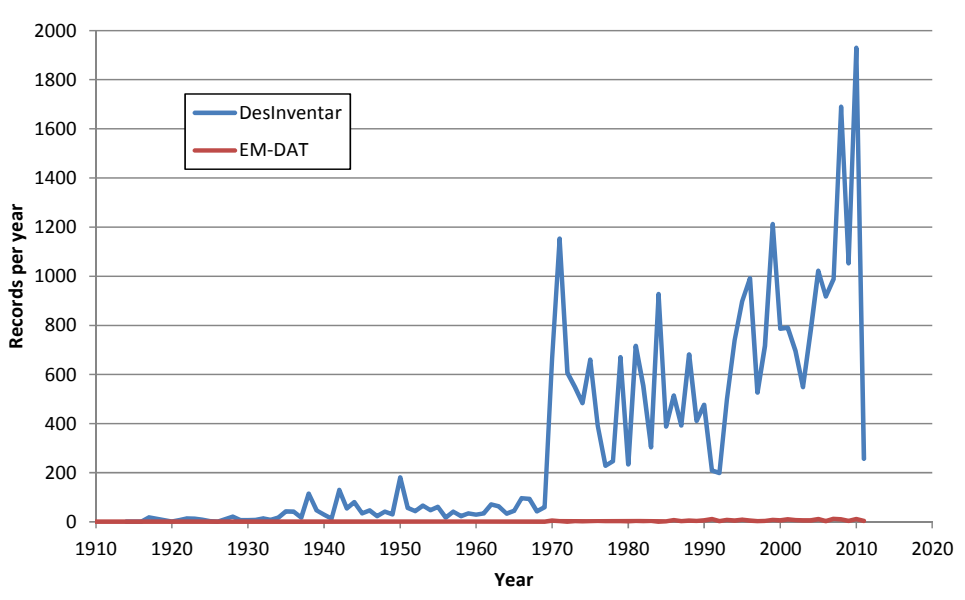

Figure $\underline{5} 4$ Records available per disaster database for Colombia

As noted previously, the DesInventar database has fields that are in line with the proposed economic loss model, among which the damaged houses, the destroyed houses and the meters of damaged roads. Also, it must be noted that the DesInventar disaster database contains a high number of records with minor damages and within a large area; these are considered as small disasters that have occurred over rural and peripheral areas. Therefore the records of the DesInventar database are considered as the consequences of the natural hazards upon the vulnerable society sectors. 
The DesInventar records to be used in the proposed methodology have to be filtered, aggregated and valuated. As a result, the consequences and the economic cost of the event will be obtained.

\subsection{Period of analysis}

The DesInventar disaster database try to be as extensive as possible, which means that in some cases, big and isolate records can be found (i.e. records from the beginning of the XX century or earlier). Even more, the database contains periods over which the records are scarce, due to the unavailability of information or to the high cost for searching and processing data.

Another topic to be considered is the relevance between the reported consequences and the current exposure. Taking into account that the majority of buildings are designed for a life period of 50 years, and that the level of completeness of the databases is adequate for the last 40 years, it could be assumed that the building exposure is fairly acceptable for the retrospective risk assessment. That is, we try to have a time period of records for which the exposure is somewhat similar allowing obtaining valid conclusions.

Nevertheless, we are aware of the effect that an increasing exposure could have over the risk and the expected losses; in this case, those will be even larger than the calculated using the proposed methodology if the vulnerability conditions are kept. In the case of an increased exposure along with improvements if the construction codes and practices (i.e. a reduction of the vulnerability) and/or better planning (i.e. hazard prevention) we expect that the results of the analysis will be kept.

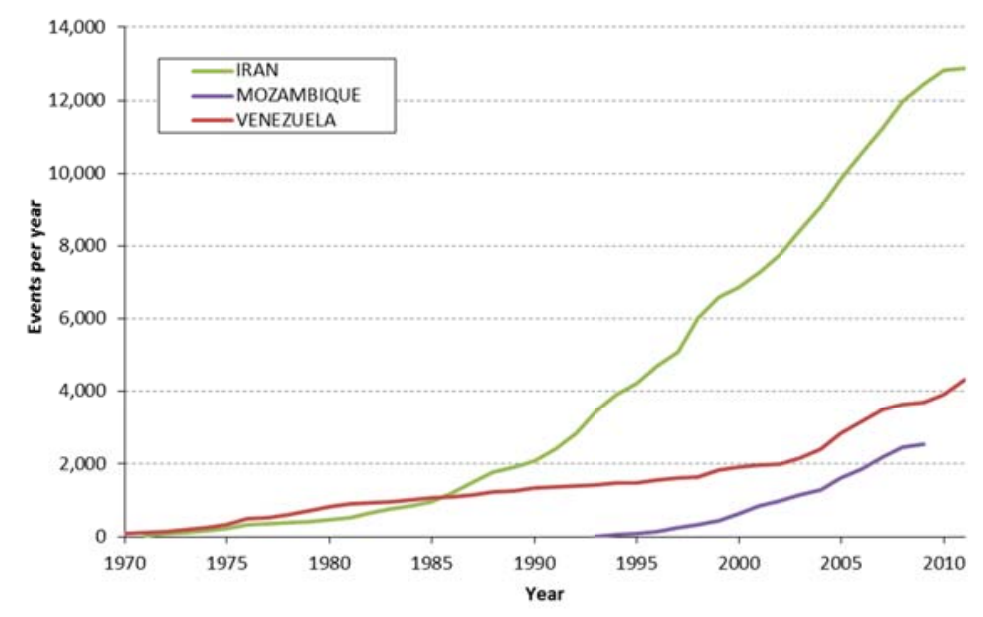

Figure 6 5 Completeness of DesInventar database

For the proposed statistical process, it is necessary to carefully set the analysis period to one for which representative results can be drawn. As showed on Figure 6Figure 5, this has to be evaluated for each case, looking for a period over which the mean frequency of events does not present abrupt changes. 


\subsection{Classification and filtering of records}

Considering that there is a large number of terms that can be used to describe the actions of a natural hazard which materializes over a region and that those terms can differ for the same event among regions of the same country it is necessary to classify each one of the recorded events on common categories. In this way, a more straight-forward methodology can be proposed, that also allow the comparison of results from different countries. Even more, many available administrative information use nonacademic vocabulary. Table 8 Fable 8 shows the considered disaster categories; their use depends on the existing hazards in the study region. In this step, no cause-effect relation will be considered, that is, the events will be classified according to their reported cause and not to their trigger event (if any, in the case of triggered disasters); the next step "Event grouping” will handle these possibilities.

Table 8 Natural hazards categories

\begin{tabular}{|c|l|}
\hline Event & \multicolumn{1}{c|}{ Description } \\
\hline Tectonic & Events caused by tectonic activity, like earthquakes and tsunamis. \\
\hline Landslide & Events caused by slope instability (e.g. mass movements, landslide) \\
\hline Volcanic & Events originating from volcanic activity (e.g. pyroclastic flows, lava). \\
\hline Hydro meteorological & Events caused by normal water cycle (e.g. Storm, hail storm, flood) \\
\hline Hurricane & Extreme hydro meteorological events (i.e. tropical storm, hurricanes, cyclones, typhoons) \\
\hline Drought & Events caused by low air humidity over a long period. \\
\hline
\end{tabular}

Besides the events belonging to one of these categories, the DesInventar disaster database also includes anthropic events. Those events were discarded from the analysis since they are the result of human activity and their occurrence does not correspond to any natural process and require very specific policies for reduction and management.

Table 9Table 9 displays the relation between the field "Cause" of the DesInventar records and the previously defined categories. This is not an exhaustive list, what means that according to the selected DesInventar database other terms could be found. The anthropic events have been filtered out, together with forest fires, which mostly are related to or caused by to human behaviors [33, 34, 35] including, but not limiting to: land conversion burning, discarded cigarettes, electric equipment sparks, etc. Nevertheless, the present methodology can be adapted to consider the effect of wildfire, based on local data and knowledge of their causes.

Table 9 Cause category relation

\begin{tabular}{|l|ccc|}
\hline \multicolumn{1}{|c|}{ Category } & & Causes & \\
\hline Tectonics & Earthquake & Tsunami & \\
\hline Volcanic & Volcanic activity & & Landslide \\
\hline Landslide & Mass movement & Typhoon & Cyclone \\
\hline Hurricane & Hurricane & Torrential flood & Change in coastline \\
\hline Hydro meteorological & Deluge & Freezing & Flood \\
& Hail storm & High tide & Fog \\
& Rains & Cold spell & Blizzard \\
& Snow storm & Tornado & Heavy winds \\
\hline Drought & Electrical storm & Drought & \\
\hline
\end{tabular}




\subsection{Event grouping}

The DesInventar database registers the effects of any single event or disaster in several records, one for each stroked location. This means that in the case of disasters striking a large area (e.g. earthquakes) one event could have all its consequences spatially dispersed on hundreds of locations. In the case of time persistent disasters (e.g. hurricanes) the consequences of the event could also be temporally distant. Therefore, a process for identifying and merging the records related to the same disaster is required.

Table 10Table 10 shows the time ranges for the same category records to be taken as caused by the same event; moreover, considering the possibility that one event could trigger another disaster, the table also includes a period of time between records of different categories on which the relation cause-effect could be assumed. The records at the same regional level (i.e. the records that share the same area code) which occurs between the time frames defined in Table 10Table 10 will be grouped together. The ranges displayed are provided as an example, as these values have to be defined by means of a more detailed analysis of the database and of the existing hazards.

Table 10 Temporal relation between categories

\begin{tabular}{|c|c|c|}
\hline Causing & Caused & $\begin{array}{c}\text { Interval of time } \\
\text { [days] }\end{array}$ \\
\hline Drought & Drought & 15 \\
\hline \multirow{3}{*}{ Hurricanes } & Hurricanes & 5 \\
\cline { 2 - 3 } & Hydro meteorological & 5 \\
\cline { 2 - 3 } & Landslides & 5 \\
\hline Hydro meteorological & Hydro meteorological & 2 \\
\cline { 2 - 3 } & Landslides & 2 \\
\hline Landslides & Landslides & 1 \\
\hline \multirow{2}{*}{ Seismic } & Seismic & 2 \\
\cline { 2 - 3 } & Landslides & 3 \\
\hline \multirow{2}{*}{ Volcanic } & Volcanic & 5 \\
\cline { 2 - 3 } & Landslides & 5 \\
\cline { 2 - 3 } & Earthquake & 5 \\
\hline
\end{tabular}

\subsection{Economic valuation}

For the economic valuation of the losses induced by the processed events, only direct losses will be considered. As explained in section 3, the calculated cost can be considered as the minimum resources that the local government was supposed to spend restoring the lost assets for social equivalent ones, in order to cope with its fiscal responsibility.

Additionally to the quantitative fields accounting the consequences of the disaster (i.e. damaged houses, destroyed houses, schools, health centers, roads), DesInventar also contains logical fields, expressing if any damage can be expected over those same fields (e.g. has_destroyed_houses). In the cases that a logical field shows damage, but the corresponding quantitative field is empty (or zero) a unitary element will be assigned.

The proposed relations of the economic valuation model are based on simplifying assumptions. Those are made with the best possible criteria, considering the use and 
application of the expected results. The main objective is to obtain a minimum cost of the previous disasters, in a simple and replicable methodology. Therefore, the current model is open to improvements.

\subsection{Results}

Once the economic valuation of the processed events is completed, it is possible to observe the overall impact of the disasters upon the society during the studied period. The total loss and the average annual loss (AAL) for all the events and by category are some of the direct results available. The obtained values can be considered as conservative for the effects of the disaster (due to the use of a simplified model, the number of fields employed and the assignation of a social replacement value). Nevertheless, these results are representative of the impact, especially for small and medium disasters which are constantly ignored by the authorities because of their apparently and individual low cost. Several results obtained for Colombia during the development of this methodology for the GAR11 report [7] are shown in the following.

Figure 7Figure 6 shows the percentage of threatened municipalities of Colombia respecting to the disaster category losses.

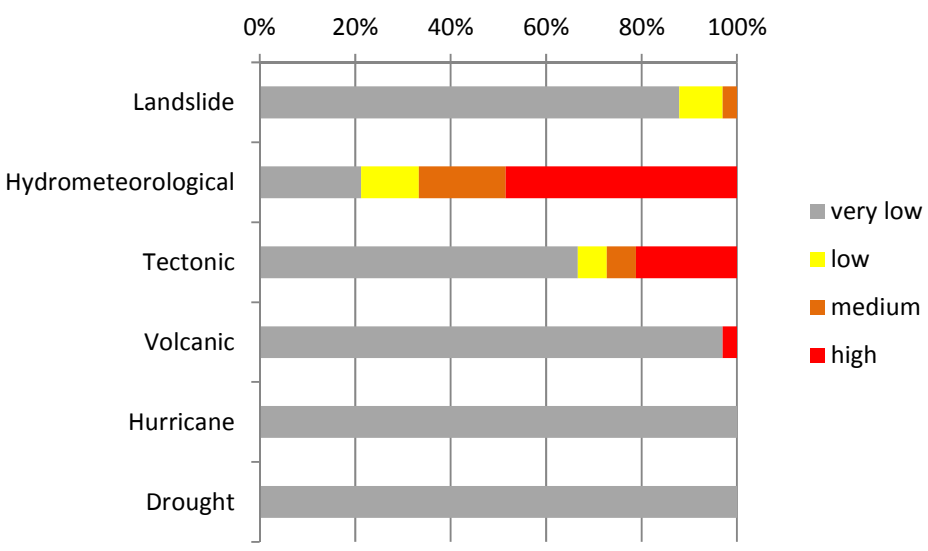

Figure 76 Percentage of threatened municipalities of Colombia by hazard category level

Figure 8Figure 7 compares the losses due to the studied categories for different return periods. In this particular case it also shows how in the short return periods are the hydro-meteorological events the ones that most impact the communities and the life and properties of their members. 


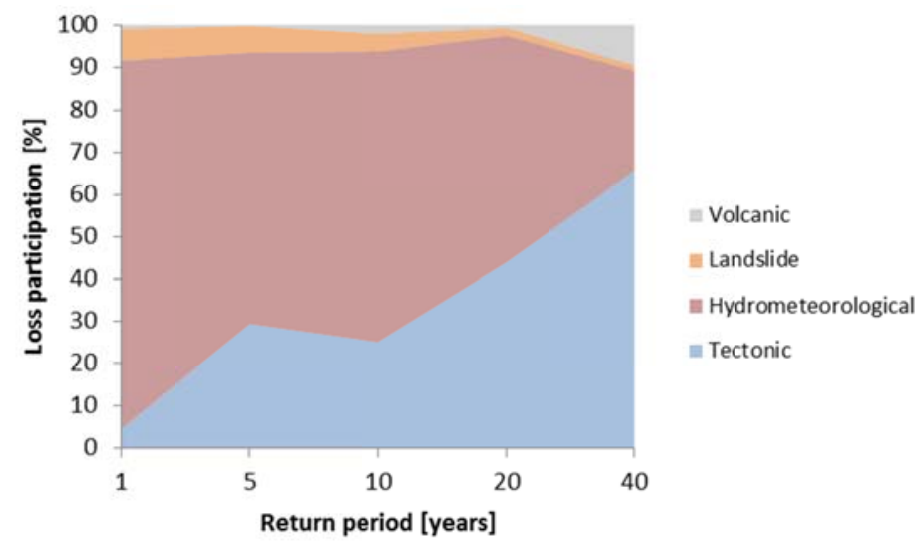

Figure 87 Loss percentage comparison per event return period and hazard category for Colombia

Figure 9Figure 8 shows the historic behavior of losses, together with their accumulated value over time. It also shows the graphical representation of the AAL, and it can be seen how saving or accumulating this value over a large period of time all the losses will be compensated.

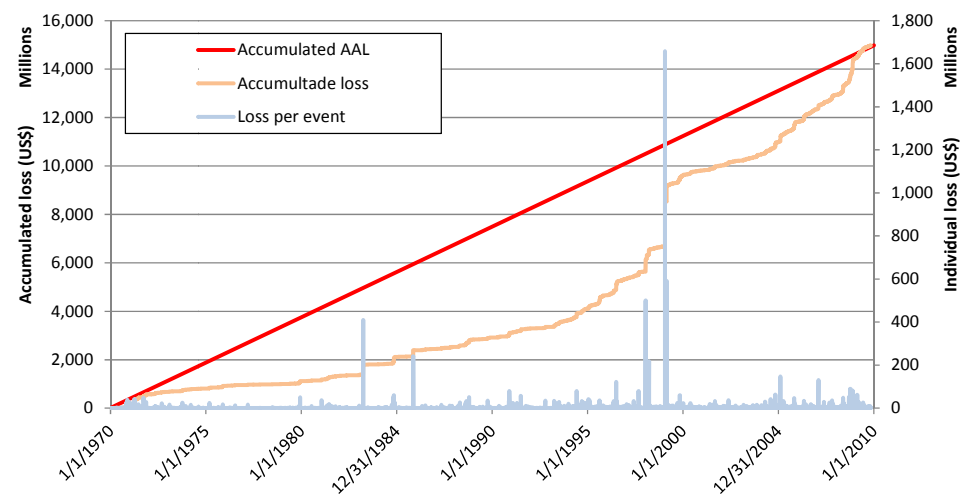

Figure 98 Historic behavior of losses for Colombia over 40 years;

The historical behavior of the economic losses, by time periods is shown in Figure 10Figure 9. These periods could be governmental periods which show the amount of resources required to cope the fiscal responsibility during previous stages.

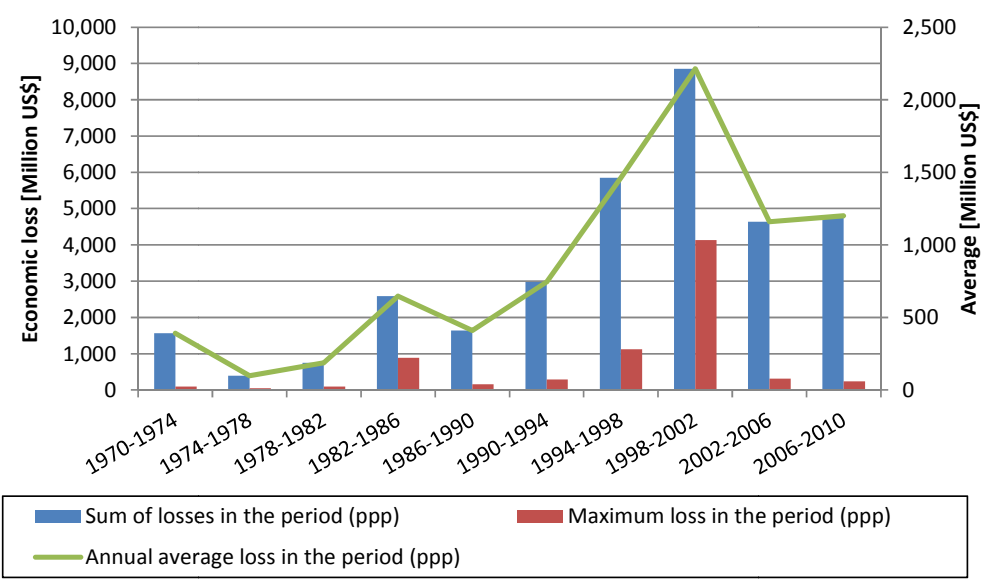

Figure $\underline{109}$ Historic behavior of disaster losses per time period for Colombia 
Finally, as the obtained results represent economic losses, a frequency analysis is possible for each of the categories of natural hazard and for all the categories. Thus, the retrospective or empiric loss exceedance curve is determined. This curve shows the historic frequency with which each loss is reached or exceeded. The loss exceedance curve, LEC, provides the most complete description of risk. It displays the relation between a given loss (usually economic) and the annual rate with which that specific loss will be reached or exceeded. Figure 11Figure 10 shows a LEC which correlate an expected loss (horizontal axis) with their estimated frequency (left vertical axis). As the frequency is the inverse of the return period, the loss can also be represented as a function of the return period (the right vertical axis).

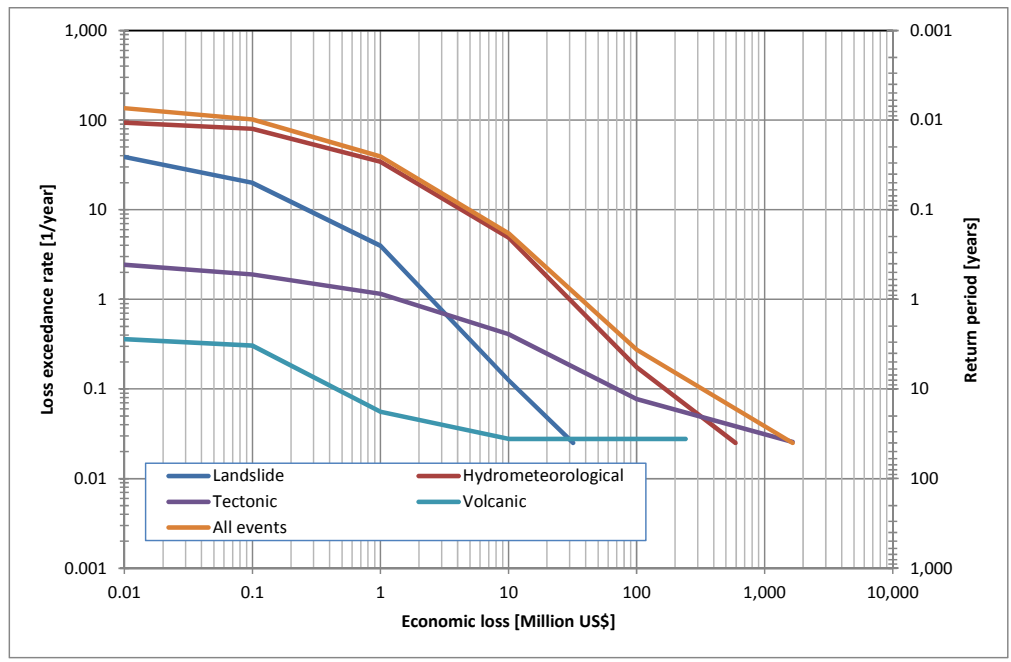

Figure 1110 Loss exceedance curve, by category and for the total of events for Colombia

\subsection{Applications of the proposed methodology}

Some results obtained during the developing of the methodology for the GAR reports $[7,8]$ are shown in Table 11Table 11; these correspond to some American countries only and are shown in the Figure 12 Figure 11, where it can be seen the impact (in absolute and relative numbers) that the disasters had. Results for other countries of Asia and Africa can be found in the GAR reports and in the GAR background papers [36, 37].

Table 11 Retrospective average annual loss

\begin{tabular}{|l|c|c|c|}
\hline & US Millions & \% GDP & \% GFCF \\
\hline Bolivia & 6.00 & 0.03 & 0.13 \\
\hline Colombia & 360.00 & 0.11 & 0.45 \\
\hline Costa Rica & 14.52 & 0.04 & 0.18 \\
\hline Ecuador & 29.13 & 0.04 & 0.15 \\
\hline El Salvador & 131.63 & 0.57 & 3.96 \\
\hline Guatemala & 63.38 & 0.13 & 0.90 \\
\hline Honduras & 45.59 & 0.26 & 1.05 \\
\hline Mexico & $2,540.00$ & 0.22 & 1.10 \\
\hline Peru & 315.20 & 0.18 & 0.74 \\
\hline Venezuela & 104.41 & 0.03 & 0.19 \\
\hline
\end{tabular}




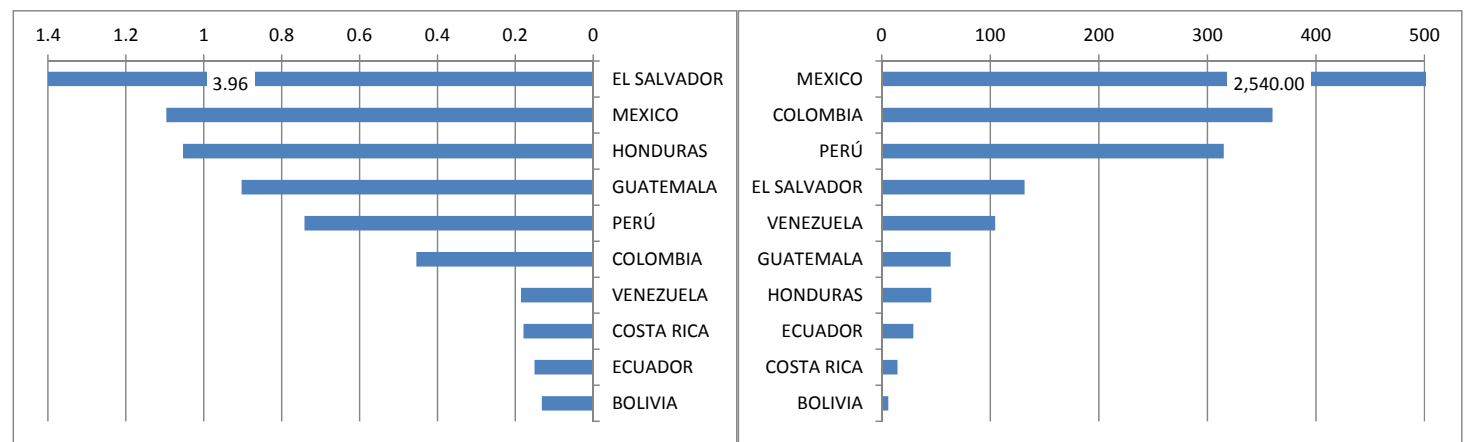

Figure 1211 Retrospective average annual loss (Left: As \%GFCF, Right: US\$ Millions)

The retrospective LEC is also an important result which is shown in Figure 13Figure 12 for the studied American countries. This result allows observing the frequency with which small, medium and big disasters hit these countries in the past.

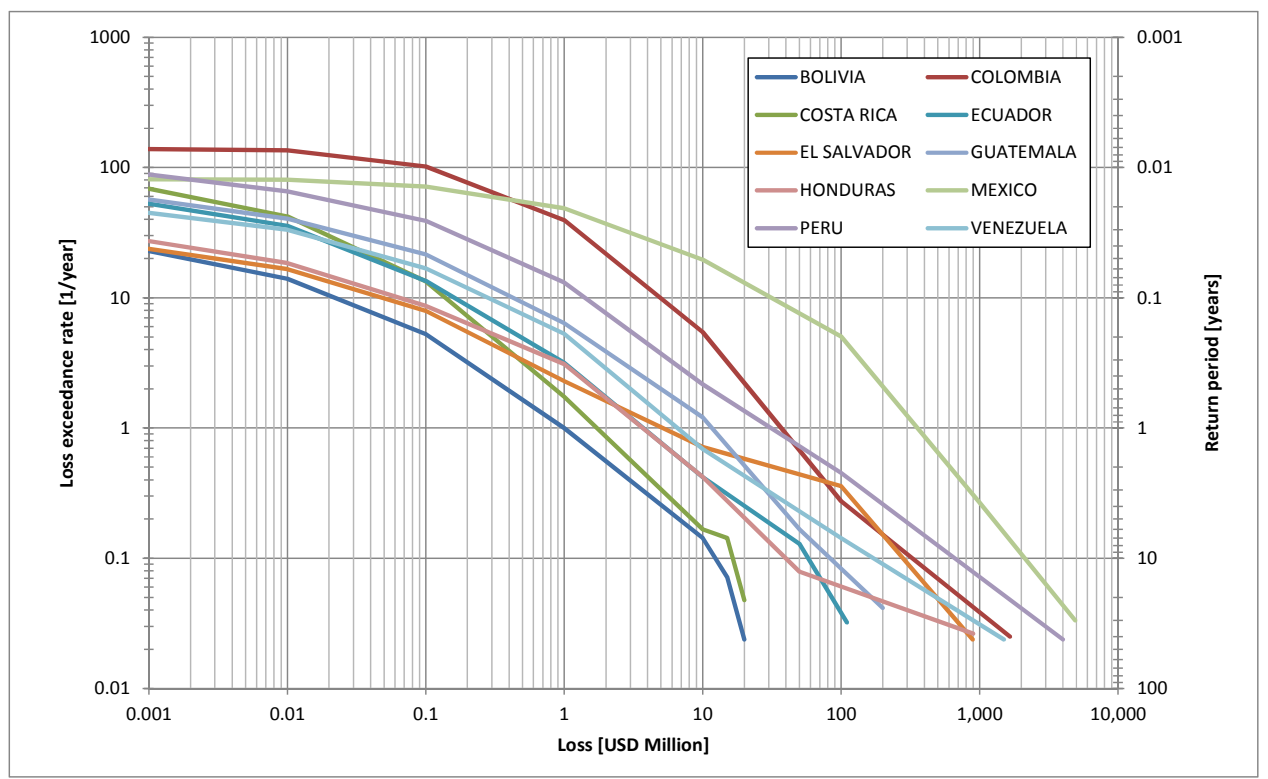

Figure 1312 Retrospective LECs for the studied American countries

All the performed analyses are showing the complex situation of the communities and treasury departments due to the natural hazards, particularly due to the small disasters, allowing to communities and to the corresponding agencies to understand the individual and cumulative effects of the natural hazards, if no change is made regarding risk reduction and risk management policies.

The results obtained from the analysis represent the economic losses that the previous disasters produced in the affected communities, and show the amount of lost resources that, in the majority of the events, were replaced by the affected communities, reducing their adaptive capacity and their systems of production.

These results also represent the risk due to natural hazards, in particular those responsible for the small disasters. The small disasters need a different approach for their assessment, because they are depending on local characteristics and large and 
comprehensive models that account for the disperse risk over a big area will require an important amount of information and computational resources not yet available.

\section{Conclusions}

The possibility of assessing the effects of previous small natural disasters allows the identification and characterization of the natural hazards and, at the same time, allows accounting for their accumulated effect. The proposed methodology addresses this problem in a systematic way and it can be used for a broad number of records available from disaster databases. Nevertheless, it is important to remark that the resolution and the reliability of the economic evaluations are far more accurate in the individual analysis of events than in their collective analysis.

Employing similitudes with the insurance industry, it is possible to correlate the previous damages and losses to the future risk caused by small disasters (at least at short term). This is particularly helpful when thinking in the complexity of modeling the effect of small disasters over large areas considering, among others, the amount of data, the spatial resolution and the susceptibility of the results. This retrospective risk assessment and its different metrics (i.e. the Loss Exceedance Curve or LEC and, the Average Annual Loss or AAL) is of special importance for small communities, which are the more likely to be hit by small disasters and, in many cases, are ignored by planning authorities.

The proposed retrospective LEC curve is of special relevance for governments, treasury secretaries and international organizations. The policy makers do not calculate this segment of the LEC, which largely characterize the risk due to minor disasters. Even more, when the retrospective LEC is combined with the prospective LEC (obtained from a catastrophic risk assessment) it conforms the hybrid LEC [10] providing a more robust and comprehensive profile which can describe, simultaneously, the country's extensive and intensive risk.

The reliability of the analysis is based on the information provided by the disaster databases employed. Thus, there is a permanent need for reviewing and auditing the different database records and its information sources. Other elements like the chosen variables, the replacement items and their cost could be improved in country specific assessments.

\section{Acknowledgements}

This work has been sponsored by UNISDR, and has been used as a background paper in the GAR report $[7,8]$. We want to thank the following local institutions for their help and collaboration: Colombia (INGENIAR, ITEC) and Nepal (NSET). We also thank to the Florida International University for their support in the $\mathrm{PhD}$ studies of César Velásquez. This work has been also partially sponsored by the European Commission (project DESURBS-FP7-2011-261652). The authors are also grateful for the support of 
the Ministry of Education and Science of Spain, project "Enfoque integral y probabilista para la evaluación del riesgo sísmico en España, CoPASRE” (CGL2011-29063).

\section{References}

[1] A. H. Barbat, L. G. Pujades, N. Lantada and R. Moreno, "Performance of buildings under earthquakes in Barcelona, Spain”, Computer-Aided Civil and Infrastructure Engineering, 21, 2006, 573-593.

[2] A. H. Barbat, M. L. Carreño, L. G. Pujades, N. Lantada, O. D. Cardona and M. C. Marulanda, "Seismic vulnerability and risk evaluation methods for urban areas. A review with application to a pilot area”, Structure and Infrastructure Engineering, 6, 12, 2010, 17-38.

[3] A. H. Barbat, M. L. Carreño, O. D. Cardona y M. C. Marulanda, "Evaluación holística del riesgo sísmico en zonas urbanas”, Revista internacional de métodos numéricos para cálculo y diseño en ingeniería, 27(1), 2011, 3-27.

[4] M. L. Carreño, O. D. Cardona and A. H. Barbat, "Método numérico para la evaluación holística del riesgo sísmico utilizando la teoría de conjuntos difusos”, Revista internacional de métodos numéricos para cálculo y diseño en ingeniería, 30(1), 2014, 25-34.

[5] Marulanda, M. C., Cardona, O. D., \& Barbat, A. H. (2010). Revealing the socioeconomic impact of small disasters in Colombia using the DesInventar database. Disasters, 34(2), 552-570. doi:10.1111/j.1467-7717.2009.01143.x

[6] Cardona, O. D., Ordaz, M. G., Marulanda, M. C., \& Barbat, A. H. (2008b). Estimation of Probabilistic Seismic Losses and the Public Economic Resilience-An Approach for a Macroeconomic Impact Evaluation. Journal of Earthquake Engineering, $12,60-70$.

[7] UNISDR (2011). GAR2011: Global Assessment Report on Disaster Risk Reduction: Revealing risk, redefining development. Geneva, Switzerland: United Nations International Strategy for Disaster Reduction.

[8] UNISDR (2013) GAR2013: Global Assessment Report on Disaster Risk Reduction - From shared risk to shared value: The business case for disaster risk reduction. Geneva, Switzerland: United Nations International Strategy for Disaster Reduction.

[9] Velásquez, C. A., Cardona, O. D., Yamin, L. E., Mora, M. G., \& Barbat, A. H. (2011). Curva de excedencia de pérdidas híbrida para la representación del riesgo. Cuarto Congreso Nacional de Ingeniería Sísmica, Granada, España.

[10] Velásquez, C. A., Cardona, O. D., Mora, M. G., Yamin, L. E., Carreño, M. L., Barbat, A. H. (2014). Hybrid loss exceedance curve (HLEC) for disaster risk assessment. Natural Hazards Journal. DOI: 10.1007/s11069-013-1017-z.

[11] ERN-AL (2010). CAPRA, Compressive Approach for Probabilistic Risk Assessment. World Bank, InterAmerican Development Bank. Retrieve from ecapra.org. 
[12] CRED (n.d.). EM-DAT: The OFDA/CRED International Disaster Database www.emdat.net. Brussels, Belgium: Université catholique de Louvain. Dirección web http://emdat.be/.

[13] OSSO (n.d.) Desinventar.org - DesInventar Project. Cali, Colombia: Corporación OSSO. http://desinventar.org/en/.

[14] UNISDR (n.d.). Desinventar.net - DesInventar Disaster Information Management System, Version 9.5.12-2011. Geneva, Switzerland: UNISDR. http://www.desinventar.net/index.html.

[15] Marulanda, M. C., Cardona, O. D., \& Barbat, A. H. (2008). La gestión financiera del riesgo desde la perspectiva de los desastres: Evaluación de la exposición fiscal del estado y alternativas de instrumentos financieros de retención y transferencia del riesgo. CIMNE IS-61. Centro Internacional de Métodos Numéricos en Ingeniería, Barcelona, España.

[16] ECLAC. (2003). Handbook for Estimating the Socio-economic and Environmental Effects of Disasters of Disasters.

[17] Marulanda, M. C. (2013). Modelación probabilista de pérdidas económicas por sismo para la estimación de la vulnerabilidad fiscal del Estado y la gestión financiera del riesgo soberano, Tesis Doctoral, Barcelona, España: Universidad Politécnica de Cataluña, UPC.

[18] Subsecretaria de desarrollo urbano y vivienda (2007). Los programas de vivienda social y la inclusión urbana - Argentina. XVI Asamblea de ministros y autoridades máximas de la vivienda y el urbanismo en América Latina y el Caribe - Minurvi. Chile.

[19] Ley No 26912. Ley de Promoción del acceso de la población a la propiedad privada de vivienda y fomento del ahorro, mediante mecanismos de financiamiento con participación del sector privado. República de Perú.

[20] INURBE (1995a). Medio siglo de vivienda social en Colombia 1939-1989. Instituto de Crédito Territorial - ICT, Ministerio de desarrollo económico, Instituto Nacional de Vivienda de Interés Social y Reforma Urbana - INURBE. Bogotá, Colombia.

[21] INURBE (1995b). Cartilla para usuarios - Modelos replicables para asistencia técnica. Instituto Nacional de Vivienda de Interés Social y Reforma Urbana - INURBE. Bogotá, Colombia.

[22] Decreto 2083 de 2004. República de Colombia. Diario oficial 45595. 30 de Junio de 2004

[23] Decreto 2060 de 2004. República de Colombia. Diario Oficial 45590. 25 de Junio de 2004.

[24] Decreto 0075 de 2013. República de Colombia. Diario Oficial No. 48.682. 23 de Enero de 2013 
[25] Sánchez Corral, J. (2010a). La vivienda "Social” en México: Pasado - presente futuro?. Sistema nacional de creadores de arte emisión 2008; Primer informe Agosto 2009 - Julio 2010.

[26] Sánchez Corral, J. (2010b). Vivienda social: factores que influyen en la producción de vivienda en México. Sistema nacional de creadores de arte emisión 2008; Primer informe Agosto 2009 - Julio 2010.

[27] Ley No. 13728. Plan nacional de viviendas. República Oriental del Uruguay. Diario Oficial No 17982. 27 de Diciembre de 1968.

[28] Compass International (2012). 2012 Global construction cost and reference yearbook 12th annual edition. Compass International Consultants Inc. Morrisville, USA.

[29] World Bank Group (2012a). GDP per cápita 2011 - Indicators | Data. World Bank Group. Dirección web: http://data.worldbank.org/indicator

[30] ROCKS (2002). Road Cost Knowledge System. World Bank Group. http://www.worldbank.org/transport/roads/rd_tools/rocks_main.htm

[31] BLS (2013). Inflation calculator: Bureau of Labor statistics. http://www.bls.gov/data/inflation_calculator.htm

[32] World Bank Group (2012b). Roads, paved (\% of total roads) - Indicators | Data. World Bank Group. Dirección web: http://data.worldbank.org/indicator

[33] FAO (2007). Fire management - Global assessment 2006. Food and Agriculture Organization of the United Nations. Rome, Italy.

[34] WWF (2005). Incendios forestales - ¿Por qué se queman los montes españoles?. WWF/Adena. Madrid, España.

[35] European Parliament (2008). Forest fires: causes and contributing factors in Europe. European parliament's committee on the Environment, Public health and Food safety. Brussels, Belgium.

[36] ERN-AL (2011). Probabilistic modelling of natural risks at the global level: the hybrid loss exceedance curve. Development of methodology and implementation of case studies - Phase 1a: Colombia, Mexico and Nepal. GAR 2011 Background paper. Ginebra, Suiza: EIRD/ONU.

[37] CIMNE, EAI, INGENIAR \& ITEC. (2013). Probabilistic Modelling of Natural Risks at the Global Level: The Hybrid Loss Exceedance Curve. Back-ground Paper prepared for the 2013 Global Assessment Report on Disaster Risk Reduction. 